\title{
The Anticipated Impacts of Road Pricing on the Quality of Life in Prague City Centre
}

\author{
J. Zelinková* \\ Department of Urban Engineering, Faculty of Civil Engineering, Czech University of Technology, \\ VŠB-Technical University of Ostrava, Ostrava, Czech Republic \\ * Corresponding author: jana.zelinkova@mdcr.cz
}

DOI: $10.2478 / \mathrm{V} 10158-011-0002-\mathrm{Z}$

\begin{abstract}
Growing traffic in urban areas is linked with the increasing problems of congestion and environmental degradation. In response to this there are a range of potential instruments for dealing with traffic-related issues in urban areas, one such option being road pricing. Congestion-charging schemes have been successfully implemented in many cities; however the Czech Republic does not have any experience in this field. The future impacts of ETC (Electronic Toll Collection) if implemented in Prague were obtained from transport models. The decision on the efficiency of this instrument with respect to the expected Quality of Life (QoL) has been acquired as a result of the Delphi method process.
\end{abstract}

KEY WORDS: Congestion, congestion pricing, QoL, Delphi method.

\section{INTRODUCTION}

The frequency of the appearance of traffic congestions, and their intensity and duration in urban areas are usually tightly connected with urban economic development, employment, housing and cultural policies that make people want to live and work relatively close to each other, and attract firms to benefit from the gains in productivity thus derived (OECD/ECMT, 2007). Congestions are likely to continue to increase in locations where the population and city economies are growing, transport infrastructure development does not follow the road networks capacities required growth, and population has not been motivated enough to apply public transport alternatives instead of individual vehicle transport. Congestions cause traffic jams, slower speeds, and increased travel times which impose costs on the economy and generate multiple effects on urban regions and their inhabitants. It also has a range of indirect impacts, including environmental (air pollution, noise) and resource ones, impact on the QoL, measured, for example, by stress and safety, as well as on non-vehicular road space users. Especially due to these negative impacts, ways to reduce congestion have been sought. There are two approaches on how to reach this, either based on increasing the roads system's capacity (supply), or by reducing traffic (demand). The traditional road administration's approach to handling current and expected future traffic demands relies on adding more capacity over the whole of a route, creating new routes, and traffic management improvements. Additionally, various instruments have been implemented to regulate the demand for transport and thereby regulate traffic itself: direct and indirect taxes on vehicles and on petrol, higher quality of public transport, traffic regulations, and parking restrictions. Development within information and communication 
technology has also improved the possibility of using various forms of electronic fee collection.

Road pricing as a policy to alleviate congestion, environmental, and other problems related to urban and interurban road transportation, however, has not been implemented on a broad scale. It is widely considered to be a radical and controversial policy, as the public and politicians do not seem to be convinced of the benefits, either to society or to themselves. On the other hand, there are also long-lasting disputes among academics, especially concerning the application of the concept of marginal road pricing (Jensen-Butler, 2008).

\section{WHY ROAD PRICING}

The idea of road usage fee/toll collection as an instrument to tackle road congestion is based on an economic theory from the early 1960s in which authors developed the standard road congestion analysis to demonstrate that the market equilibrium derived from non priced road users in excessive congestion. The key was to set the price of driving equal to the social marginal costs that would reduce traffic to its optimal level. When talking about the purposes of road pricing it usually refers to:

- Collection of revenues;

- Reduction of traffic and nuisance (negative externalities, such as congestion, environmental damage, noise, etc.);

- Promoting efficiency.

The longest standing urban road pricing scheme was pioneered in Singapore as an area licensing scheme in 1975; in 1999 it was replaced with an electronic road pricing scheme (ETC). The purpose of the system is to reduce traffic in order to increase accessibility in selected area. The basis for the charge is to achieve a target-speed that gives improved accessibility. If the average speed drops, the fees increase, and vice versa. The fees are revised every third month.

In the case of Norwegian cities (Bergen, Oslo, Trondheim, Kristiansand, and Stavanger) where a toll was introduced during the years 1986 - 2001, the original target was to collect revenue to carry out specific investments that would take too long to be completed.

Both London and Rome suffered from severe congestion and environmental problems. In Rome the pricing system, which comprises of charges for permits to access the central area, is still quite limited. Clearly, the most important example in Europe is represented by ETC installed in London, where the urban road pricing was introduced on February 17, 2003 as a brainchild of the first elected mayor of London, Ken Livingstone. He had three major objectives in introducing the charge: raising revenue, promoting public transport, and, of course, reducing congestion. Initial impressions were that the charging system was very successful, achieving a $20 \%$ reduction in traffic with none of the major problems that were not predicted. However, over time London has gone through various phases with a change of price and an extension of the size of the charged zone.

- 2003, Feb. 17: charge £5.00, charged area, $22 \mathrm{~km}^{2}$ (London central business district, major part of Westminster);

- 2005, July 5: charge $£ 8.00$;

- 2007, Feb. 17, expansion of the charging zone (Western extension);

- 2011, Jan. 4, charge $£ 10.00$, Western extension switched off. 
Finally the congestion returned to the initial level. The reasons have to be evaluated; however, as a result of this outcome the Western extension was excluded from the charging area, and the charge was increased to $£ 10.00$.

\section{ETC IN THE CZECH REPUBLIC}

Evidently, there are globally recognized strong barriers to urban ETC implementation that are the main reasons why this instrument has been applied quite rarely. Ninskanen et al. (2003) made the following classification:

- Technological and practical barriers;

- Legal and institutional barriers;

- Acceptability of related barriers (public, business, and political acceptability).

The Czech Republic belongs to the group of countries where urban ETC has not so far been implemented. Even so, there are noticeable signals that, in the case of the capital city, Prague, some introductory processes, namely in the area of surveys and studies based on transport modeling, have already been carried out (i.e., studies provided to the Prague Municipality by Evions, a.s. 2008, published, however, in Czech only).

Referring to the barriers mentioned above, in the case of Prague, all of the barriers shall be taken into account when discussing the possible implementation of urban ETC. Each city where urban ETC is accepted for upcoming implementation should act independently in relation to the stated future objectives. In the case of Prague, the major targets have been stated by the Prague municipality as the following:

- Improving the environment and the protection of cultural heritage;

- Improving the transport situation in the city centre;

- Building the instrument for managing traffic flows in the city centre;

- Multi-functional systems (security, transport modeling).

With regard to the accessibility of relevant data and transport modeling outcomes the aim of the evaluation is the assessment of the impact of congestion charging on the QoL in the city centre (within the zone of charging). QoL is a multidimensional construct that may be defined as the extent to which important values and needs are fulfilled. QoL refers to well-being, conceptualize either in term and objective living conditions, or as a person's own assessment of his or her well-being in life, or both. Therefore, the group of parameters has been chosen, and their combination has been appraised as representative enough and the QoL represents in this special case. These are as follows:

- Economic development of the charging zone (the impact of congestion pricing on economic activities and development);

- Environmental living parameters (the impact of the instrument on emissions and noise burden);

- Quality and accessibility of alternative transport (above all urban public transport).

The selection of the above-mentioned parameters relates to both the accessibility of the relevant data and modeling instruments, and the experience of the cities which have already experienced the implementation of congestion pricing.

The outcome of the transportation models indicates that a result of congestion charging 
implementation is a decline in the amount of traffic. This fall varies depending on the chosen charging zone and congestion charging level.

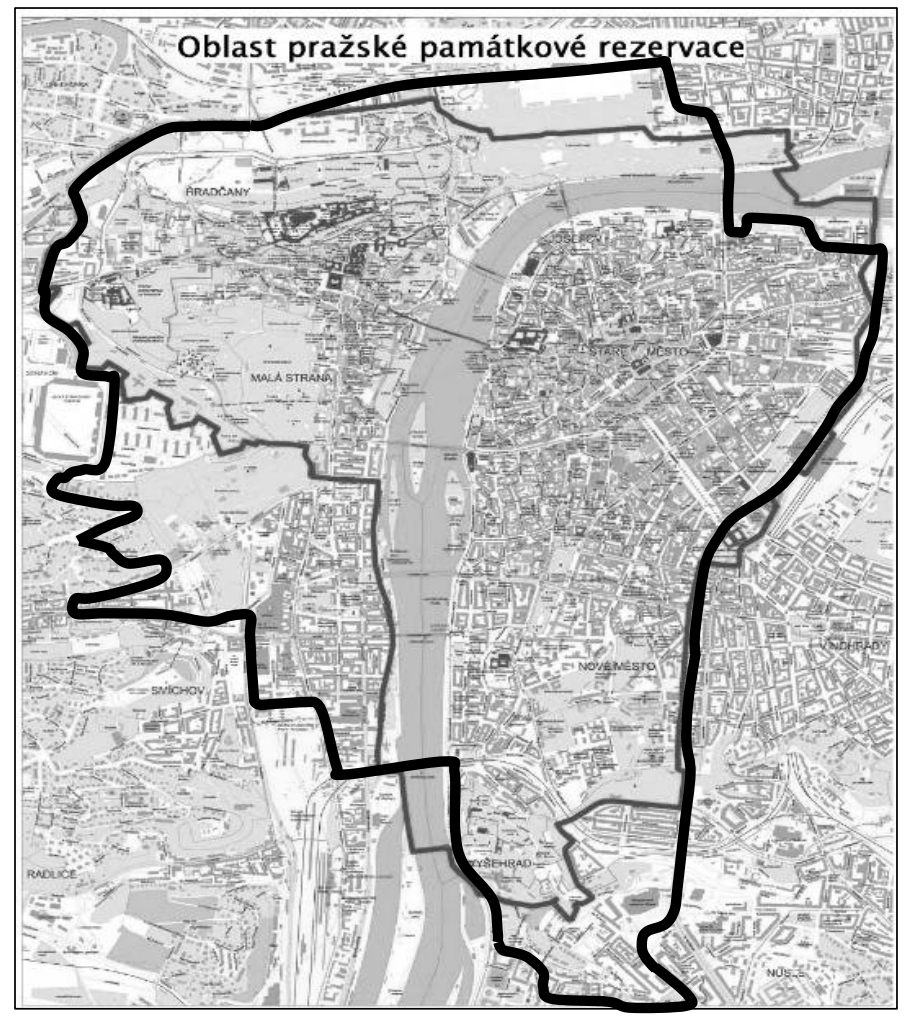

Figure 1: Largest option of congestion charging zone (boundary of the zone is marked in green)

In the target year 2020, with the planned Prague road network, comprising of the urban ring and the Prague ring road, seven radial roads, and two conjunctions, a reduction in the number of vehicles is expected of between 12 and $25 \%$ (up to 35 - 74 thousands vehicles daily), which corresponds to experience gained from abroad: in the case of London a year after the congestion charge introduction the drop was of approx. $18 \%$, in case of Stockholm about $21 \%$. With each of the tested versions the fact that part of the transport from the city centre will be transferred to the bypass roads is be counted with.

Generally, the urban ETC implementation will result in a redistribution of traffic flow on not only the road net within, but also outside of, the suggested charging zone. It can be anticipated that the decline in the number of vehicles in the city centre (due to the congestion charging) will proportionally cause an increase of the transport burden on the alternative bypass roads as a result of the effort of some drivers to drive close to the charging zone boundary; others will decide for alternative forms of transport, or even decide not to drive into the charging zone. Urban ETC therefore represents an instrument that changes the behavior of the individual vehicle users.

The reduction in number of vehicles in the charging zone shall logically imply less pollution caused by individual traffic. This presumption was verified in five reference subareas with a higher concentration of pollutants and noise. The results confirmed the expectations of pollutant concentration and noise level changes. Concerning the case of emissions within the charging zone due to congestion charging a decrease in the emission concentration levels of pollutants was identified. Outside of this zone, especially with respect to the increase in the transport amount on the alternative bypass roads, the emission 
concentrations increased. The quality of air in the charging zone was improved, due to the reduced number of vehicles and the density of congestion; however, every situation is specific and depends on the actual atmospheric conditions (the appearance of frequent inversions), wind directions, together with the local landscape morphology.

In the case of noise load examination, again only in the reference points, the important influence of the congestion charging implementation has failed to be proved. For this reason noise impact can be understood as a less important parameter.

Epidemiological and toxicological studies indicate that transport-related air pollution can affect a number of health outcomes; however, commonly accepted selective quantification has not been yet accepted. Transport traffic pollutants contribute to the increased risk of death, particularly via cardiopulmonary syndromes, and pollutants increases the risk of non-allergic respiratory symptoms. Laboratory studies point out the fact that transport-related air pollution increases the risk of developing an allergy and can exacerbate symptoms - in particular, in susceptible subgroups (Laden et al., 2006). However, according to the WHO the relation between adverse effects on health and exposure to transport-related air pollution still needs to be elaborated and more research is needed, e.g., to clarify which constituents of traffic emissions are responsible for the observed adverse effects (WHO Regional office for Europe, 2005). Based on the conclusions and recommendations of the WHO it can be agreed that the only possible solution in order to avoid further traffic-induced harm to human health is to reduce the total growth in traffic, especially in urban areas (WHO Regional office for Europe, 2000). In this sense, congestion charging certainly represents an important instrument.

The public transport system of Prague is evaluated as one of the most advanced systems in Europe. It is used by almost four millions passengers daily. Some limited and selectively spread capacities are still identified in the existing public transport system available for passengers who decided to change from their vehicle transport to public transport. These capacities can be used without the need for principal changes in the current regime. Any additional financial resources stemming from ETC implementation would mean, in the case of their investment into public transport, an important improvement in its service density coverage and service quality.

Implementation of ETC in Prague as a transport system control tool represents an extremely sensitive topic. It is not a only technical, but also a broad sociological, and, therefore, surely also a political issue. Therefore, urban ETC technical solutions, not only in Prague, but also in the other cities of the CR, as well as in other places in Europe, North America, and Asia, are far ahead of political decisions on their implementation.

\section{DELPHI METHOD}

In order to assess the efficiency of selected restrictive measures the Delphi method was accepted for evaluation, as it enables representative multilateral appraisal of a problem and adds independent experts' statements to the issue. Ten independent experts participated in the survey - these were representatives of the state administration (Ministry of Transport, State Fund for Transport Infrastructure), the City of Prague (Technical Road Administration of Prague), the private sector (IBM Czech Republic Ltd., MOTT MACDONALD Praha, Ltd., INTENS Corporation Ltd., Czech Railways, and the University (CTU Prague, Faculty of Transportation Sciences). Selected experts represented the following branches: the strategy of transport development in the CR, ITS conception and implementation in the CR, financing of transport infrastructure development in the CR, consultancy (economic - technical), in the transport systems branch, economics and the management of transport systems, and transport process modeling. Each of the experts worked completely independently 
with the aim of avoiding the psychological barrier stemming from the immediate reaction resulting from direct contact. The document, comprising all the criteria with comments, was drawn up in order to reflect all positives and negatives from possible road pricing implementation. The experts focused on overall assessment, including not only the impacts of the toll in the charging zone, but also the impacts in the area outside of the charging zone, where negative effects can be identified as a result of the traffic increase on the bypass road systems. The questionnaire comprised of the following hypothesis:

- The ETC presents a useful instrument for traffic flow regulation in the charging area with the impact of a decrease in congestion potential;

- The ETC has a neutral impact on the economic development of the charging area;

- It is a flexible instrument - e.g., with the height of the charge the efficiency of the instrument can be continuously increased;

- Transport models (with regard to foreign experience) enables the predication of the impacts of ETC implementation in the charging area;

- The ETC is a suitable source of investments into non-motorized transportation in a city (especially in public transport);

- The ETC is a suitable instrument for developing a given area, if the transport regulation is successful (a possible instrument of reurbanisation);

- If the transport regulation is successful the ETC may have a positive impact on monument protection;

- The efficiency of the ETC may be lower in the case of insufficient construction of transport infrastructure;

- There is lack of current data for transport models;

- The public acceptance of this instrument can be low, with possible political impact, etc.

The applied methodology was based on a two round assessment. In the first round each of the participants provides the weighting coefficient for each criterion, a value of $0-10$ with an explanation for his/ her evaluation. The results are processed by the arithmetic average. In order to eliminate the influence of extreme values the responses with the highest and lowest values were omitted. In the second round of assessment, each participant was asked to reconsider a possible correction on the basis of information provided about the outcome of the first round. The evaluation results in the second round are processed by the same method as was applied in the first round.

According to the numerical results (56.1 positive points and 52.6 negative points) the outcome from the first round can be understood as a slightly positive tendency of experts towards the road pricing implementation, as it is considered as a rather effective tool for traffic regulation in the city center. After the second round (55.685 positive points and 54.372 negative points) it can be stated that the group of experts practically reached a consensus in the number of positive and negative points. The outcome of the group of experts assessment with a wide range of knowledge and skills can be evaluated as neutral towards the effectiveness of road pricing, i.e., political representatives have to enter the decision making process on the application of this relatively controversial regulation instrument. In comparison to a relatively broad consensus of experts, politicians can change the importance of certain selected parameter(s).

To sum up, the final decision on the road pricing implementation is a question of political choice. In the case of the CR there is sufficient legislation permitting the introduction of such a restrictive instrument (this fact was mentioned in the questionnaire). The first necessary step is therefore the adoption of relevant legislation on a national level. The second step will be the decision of the Prague City Council. According to public choice theory political behavior and the decisions of individuals is driven by the same economic interests as the behavior 
of individuals on the market. The purpose is to maximize their own economic benefit (e.g., their personal wealth); in the case of politicians it is to be re-elected. Economic theory understands the motivation of politicians simply as their effort to maintain the privileged position of power, and, hence, the incentive to maintain favour with voters, respectively certain groups with major influence. This theoretical approach is consistent with the findings of the cities in which road pricing has already been introduced. Retrospectively there was stated that among the greatest barriers to the introduction of charges were political and public acceptance of this toll. In the preparatory phase of the implementation of this instrument it is therefore necessary to effectively communicate with the public. It is clear that, in general, people are against the introduction of any charge. The public, however, will be more tolerant of supporting such a regulation if they are properly informed about the objectives of the policy (i.e., solving a particular traffic problem). The proposed strategy is perceived as an effective solution to the problems, especially if the revenues are reapplied in the transport sector, and if the public have confidence in the protection of their privacy [11].

\section{CONCLUSION}

Road charging is increasingly being seen as a policy option capable of dealing with the problem of congestion in urban areas. The efficiency of this instrument is always dependent on the conditions of each city where the instrument is being introduced. In order to decide whether this measure might manage the traffic in Prague with regard to the quality of life on the basis of key findings from the traffic models the experts' survey was carried out.

Weights were determined by the Delphi method, involving a representative group of experts of different transport branches. The experts' findings were broadly neutral, therefore it can be stated that the final decision on the implementation of road pricing must be a matter of political choice. Nonetheless, the first necessary step of ETC is identified in the adoption of relevant legislation. The second step is represented by the decision of the Prague City council. Political and public acceptance of road charging belongs among the greatest barriers to its introduction. In the preparatory phase of the implementation of this instrument it is therefore necessary to effectively communicate with the public, as it is clear that in general people naturally oppose the introduction of additional charges. The public, however, may be willing to accept a pricing strategy if properly informed about the purpose and objectives of the decision, the effectiveness of instruments, if the revenue is reapplied in the transport sector, and if the protection of privacy is secured.

\section{REFERENCES}

OECD/ECMT: 2007, Managing urban traffic congestion . OECD Publishing, France.

Jensen-Butler, C., et al.: 2008. Road Pricing, the Economy and the Environment. SpringerVerlag, Germany.

Niskanen, E., et al.: 2003., Implementation of Marginal Cost Pricing in Transport Integrated Conceptual and Applied Model Analysis. MC-ICAM, Final report, Version 6.0. Project of the European Commission - DG TREN; Fifth Framework, Contract no: GRD1/2000/25475-S12.316057. 
Laden, F., et al.: 2006. Reduction in fine particulate air pollution and mortality: extended follow-up of the Harvard Six Cities Study. American Journal of Respiratory and Critical Care Medicine, Vol. 173, pp. 667-672.

WHO Regional office for Europe: 2005. Health effects of transport-related air pollution. WHO Regional office for Europe. Denmark.

WHO Regional office for Europe: 2000. Transport, environment and health. WHO Regional office for Europe. Austria.

Getting prices right: Results from the transport research programme. 1st ed. Belgium: European Communities, 2001. pp 19, ISBN 92-894-1549-5. 